\title{
POLITICAS DE TRABAJO COMO DISPOSITIVO DE PROTECCIÓN SOCIIAL: EL GOBIERNO DE LOS VETERANOS ARGENTINOS DE LA GUERRA DE MALVINAS
}

\author{
Work policies as social protection device: the government of the \\ Argentinia's veterans of the Malvinas war
}

\author{
Daniel Chao* \\ * Instituto de Investigaciones Geohistóricas (Conicet-UNNE) (Argentina) \\ I.daniel.chao@gmail.com
}

\section{Palabras clave \\ Veteranos de guerra Malvinas \\ Dispositivo \\ Gubernamentalidad}

\section{Keywords}

War veterans

Malvinas

Device

Governmentality

\begin{abstract}
Resumen
El artículo analiza el modo de gobierno de los veteranos de la guerra de Malvinas por parte del Estado argentino a partir de un conjunto de leyes, decretos y resoluciones referentes al trabajo promulgados entre 1983 y 2011. Posicionándose desde el enfoque de la gubernamentalidad, se intenta dar cuenta de la constitución y el despliegue de lo que se denomina dispositivos de protección social, al señalar cómo se presentan a nivel discursivo los problemas y las acciones necesarias para solucionarlos. El escrito se divide en tres partes. En primer término, presentamos algunas discusiones teórico-metodológicas de nuestro estudio, que ligan la analítica de la gubernamentalidad con las políticas sociales. La segunda parte se centra en delinear un marco general de la Argentina de postguerra, destacando la rareza de los excombatientes de la guerra de Malvinas dentro del panorama político y social del país. Y, por último, analizamos el corpus legal construido referido al plano laboral de los excombatientes. El texto concluye con la identificación de un número regularidades que muestran la metamorfosis de la identidad del veterano de guerra como un sujeto en riesgo de desafiliación como problematización común.
\end{abstract}

\section{Abstract}

The article analyzes the government of Malvinas war veterans by the Argentine State, based on laws of work, decrees and resolutions promulgated between 1983 and 2011. From an analytical standpoint of governmentality, we try to show the constitution of work policies as a social protection device, showing how the problems and actions needed to solve those issues are presented discursively. The text is divided in three parts. First, we present some theoretico-methodological discussions of our study, linking the fieldwork of governmentality with social policies. The second part focuses on delineating a general picture of Argentinian postwar, highlighting the scarcity of war veterans within the political and social panorama of the country. Finally, we analyze the legal corpus referred to the work realm of excombatants. The text concludes identifying a number of regularities that show the identity of war veteran's metamorphosis as a subject at risk of disaffiliation as a common problematization.

Chao, D. (2017). Políticas de trabajo como dispositivo de protección social: el gobierno de los veteranos argentinos de la guerra de Malvinas. Papeles del CEIC. International Journal on Collective Identity Research, vol. 2017/2, papel 181, CEIC (Centro de Estudios sobre la Identidad Colectiva), UPV/EHU Press, http://dx.doi.org/10.1387/pceic.17103 


\section{INTRODUCCIÓN}

Este artículo propone una visión sobre las formas en que el Estado argentino reguló algunos aspectos de la vida de los veteranos ${ }^{1}$ de la guerra de Malvinas en base a políticas sociales vinculadas al trabajo. A partir del enfoque de la gubernamentalidad y analizando un corpus de leyes, decretos, resoluciones y programas de fomento laboral, esa regulación será definida como gobierno. Ese corpus será visto como la constitución y despliegue de lo que podríamos llamar dispositivos de protección social. Desde él reconstruimos los fundamentos y atributos con que fueron presentados los veteranos respecto a sus problemas y condiciones de vida.

El escrito se dividirá en tres partes. En primer término, presentamos algunas discusiones teórico-metodológicas de nuestro estudio, centrado en la analítica de la gubernamentalidad y de las políticas sociales. Fundamentamos nuestra elección respecto al tipo de política (trabajo) y construimos una definición operativa de la noción de dispositivo de protección social. La segunda parte se centra en delinear un panorama general de la Argentina de postguerra y destaca la rareza de los excombatientes de la guerra de Malvinas dentro del panorama político y social del país. $y$, en tercer término, analizamos las leyes, decretos, resoluciones y programas sociales referidos al trabajo de los excombatientes promulgados entre 1983 y 2011 y que conforman nuestro corpus. Describimos los aspectos regulares del archivo desde dos niveles: cómo son planteados los problemas de los veteranos de guerra y qué se les propone hacer para solucionar esos problemas, es decir, cómo aparecen las "acciones sobre acciones" como categoría que se centra en el deseo de los gobernantes de conducir o modificar lo que los gobernados hacen. Finalmente, reflexionamos sobre esas regularidades para dar cuenta de la metamorfosis de lo que denominamos el problema veterano.

\footnotetext{
${ }^{1}$ Usaré indistintamente la palabra excombatiente o veterano para referirme a los exsoldados conscriptos argentinos partícipes de la guerra de Malvinas. Ambos términos son utilizados en diversos documentos estatales, más allá de las disputas entre organizaciones por la denominación que tuvieron lugar sobre todo a principios de los 90 . Ver Guber, 2004; Lorenz, 2012.
} 


\section{Problematización, GUBERNAMENTALIDAD y DISPOSITIVOS}

\subsection{Problemas y acciones sobre acciones}

En una entrevista realizada en 1984, Michel Foucault mostró la importancia de la problematización para entender que los acontecimientos que nos suceden no son naturales ni necesarios y que en sí no responden a nada por fuera de su propia historia. Es necesario abordarlos como constituyéndose en la práctica de la que son objetos $y$, por ello, la propuesta del autor es reflexionar sobre cómo se presentan -en el plano del pensamiento-como problema.

"[Esta] Elaboración de un tema en cuestión, esta transformación de un conjunto de obstáculos y de dificultades en problemas a los que las diversas soluciones buscarán aportar una respuesta, es lo que constituye el punto de problematización y el trabajo específico del pensamiento" (Foucault, 1999: 360).

El análisis se centra en "lo que ha hecho posible las trasformaciones de las dificultades y obstáculos de una práctica en un problema general para el que se proponen diversas soluciones prácticas" (ibídem: 361 ).

Esta reflexión sobre los problemas y la práctica es recuperada en la noción de gobierno como un tipo de ejercicio de poder que presta atención a la "manera en que ciertas acciones modifican otras" (Foucault, apud Dreyfus y Rabinow, 2001: 252) y abren todo un campo de respuestas posibles. El gobierno es el arte de dirigir "cosas": hombres, sus relaciones y sus relaciones con otras cosas, como un ejercicio diferente al de la soberanía (sumisión totalizadora a la ley) o disciplina (intervención individual sobre el cuerpo). El autor llamó a este ejercicio de poder gubernamentalidad (neologismo que alude a los términos gobierno y mentalidad) ligado a la "conducción de conductas" y al arte de gobernar las libertades y los deseos. Si bien Foucault se valió de aquel término para describir un modo de pensamiento, la plasticidad del planteamiento fue recuperada por otros autores para definir las acciones estatales como gubernamentalización del Estado, es decir, una práctica de gobierno que no parta definiendo lo que el Estado es y hace (i.e. un asegurador de la reproducción de las relaciones de producción) sino como el resultado de procesos históricos de prácticas de gobierno, disciplinares y soberanas. 
Para Colin Gordon, por ejemplo, si el gobierno es un conjunto de acciones sobre acciones, el arte de gobierno es el conocimiento de la acción y de cómo ejercerla. De esta forma aparece "lo pensable" en un período y un espacio concreto para los ejecutores de las prácticas de gobierno y para aquellos sobre quienes se ejecutan (Gordon, 2015: 4-5). En esa línea, Santiago Castro Gómez considera que el Estado deja de ser un "lugar" del que deriva el poder y pasa a ser visto como el resultado progresivo de relaciones de poder que fueron configurando lo estatal tal como lo podemos entender hoy (2010: 43). La cuestión subyacente es cómo las prácticas y el pensamiento sobre esas prácticas se constituyen mutuamente, se traducen, configuran la presunción de una realidad que se describe y que se muestra como conocida (crea y pone en juego conocimientos sobre ella) y es susceptible de ser intervenida para transformarla (Bröckling, Krasmann y Lemke, 2011: 11).

Este punto de vista analítico se distancia de aquellos que intentan comprender los fenómenos a partir de cuestiones exógenas o transhistóricas (como lo ideológico o las relaciones de producción), pero a su vez se desliga de la idea de racionalidad con arreglos a cálculos y fines. Para O'Malley la analítica de la gubernamentalidad

\begin{abstract}
"Se interesa en las superficies -en las palabras usadas para describir los problemas, los discursos de gobierno en términos de los cuales los sujetos son caracterizados, las categorías que son usadas para explicar las políticas- más que en cualquier supuesto sustrato determinista, tal como el orden productivo o los intereses de clase" (2006: 30).
\end{abstract}

Nuestro análisis tiene como punto de partida la búsqueda de cómo se presenta en los textos qué hacer con los sujetos a gobernar, a la vez que indaga en cómo el reino de lo político es producido y cómo la gente es invocada a moverse en líneas que se muestran más probables que otras. En todo caso, es una "investigación sobre criterios estabilizados para el 'buen gobierno' y los argumentos que lo hacen posible" (Bröckling, Krasmann y Lemke, 2011: 14). Pero su búsqueda no es propositiva, es decir, no interesa cuán efectiva sea la actividad gubernamental o cómo optimizarla, sino cómo despliega sus efectos. De allí el foco en la problematización como modo de acceso y abordaje al pensamiento político, puesto que "si la conducción de individuos o colectivos emerge para requerir conducción, esto es porque algo aparece como problemático para alguien" (Miller y Rose, 2008: 14). Ese problema es 
entendido no como algo preexistente, que espera ser revelado por quienes gobiernan, sino que debe ser reproducido como pensable, por lo tanto practicable, operable e intervenible. De allí que los documentos que analizaremos en este escrito serán interrogados a partir del modo en que formulan los problemas y de cómo los veteranos de guerra son invocados a actuar en espacios que se presentan como más probables (y mejores) que otros.

\section{DISPOSITIVOS DE PROTECCIÓN SOCIAL}

La mirada desde la gubernamentalidad nos habilita a pensar lo estatal desde "las deliberaciones, las estrategias, las tácticas y los dispositivos utilizados por las autoridades para crear y actuar sobre una población y sus componentes, de modo de asegurar su bien y evitar su mal" (Rose, 2007: 4). En este sentido, la analítica descrita se mueve en dos niveles: 1) investiga operaciones discursivas a partir de las cuales la verdad es producida y se cuestiona cómo los efectos de poder se ligan a esa verdad (haciendo énfasis en la producción de conocimiento específico); 2) al centrarse en tecnologías de gobierno (que balancean las tecnologías disciplinarias y las del yo en el pensamiento de Foucault y alguno de sus seguidores), pone el foco en los dispositivos a través de los cuales individuos y colectivos les dan forma a sus comportamientos con el otro y consigo mismos (Bröckling, Krasmann y Lemke, 2011: 11-13).

Por esta razón nuestra propuesta es abordar las artes de gobierno sobre los veteranos argentinos de la guerra de Malvinas a partir de la descripción de algunos dispositivos puestos en marcha en el ejercicio del poder. Para Giorgio Agamben, Foucault definió con la noción de dispositivo un concepto operativo de alcance general, una red de elementos o tecnologías puestos a funcionar ante urgencias de gobierno $y$, por supuesto, con efectos sobre la vida de las personas. La fuerza del término es su capacidad para establecer la pura actividad de gobierno sin fundar el ejercicio de poder en el ser. Para el autor, el dispositivo es el elemento histórico concreto (una ley, un programa, un teléfono, un manual) que orienta y tiende a producir efectos. Dice Agamben:

"Entonces para otorgar una generalidad más grande a la clase de por sí vasta de los dispositivos de Foucault, llamo dispositivo a todo aquello que tiene, de una manera u otra, la capacidad de capturar, orientar, determinar, interceptar, 
modelar, controlar y asegurar los gestos, las conductas, las opiniones y los discursos de los seres vivos. (...).No solamente las prisiones, sino además los asilos, el panoptikon, las escuelas, la confesión, las fábricas, las disciplinas y las medidas jurídicas, en las cuales la articulación con el poder tiene un sentido evidente; pero también el bolígrafo, la escritura, la literatura, la filosofía, la agricultura, el cigarro, la navegación, las computadoras, los teléfonos portátiles $y$, por qué no, el lenguaje mismo, que muy bien pudiera ser el dispositivo más antiguo" (2011: 257).

El dispositivo es entonces un instrumento concreto e histórico de un tipo de poder (el arte de gobierno) que tiene una meta concreta. En ese sentido, el objetivo de este trabajo es describir algunos de los dispositivos desplegados para el gobierno de los veteranos. Los denominaremos dispositivos de protección social, adscribiendo a la posición de Robert Castel respecto a que la protección social es un término ligado desde el inicio a la cuestión social, entendida esta como la "aporía fundamental en la cual una sociedad experimenta el enigma de su cohesión y trata de conjurar el riesgo de su fractura" (1995: 16). Esa protección refiere al "basamento de recursos y derechos que se proporciona [desde el Estado] al individuo moderno y que le permitió convertirse en un miembro de la sociedad con derecho propio" (Castel, 2010:189). En gran medida, la distribución de esos recursos se concentra en lo que se denomina políticas sociales, a las que entenderemos como una "intervención de la sociedad sobre los modos de funcionamiento de los vectores a través de los cuales individuos y grupos se integran, con grados variables de intensidad y estabilidad, a la sociedad" (Soldano y Andrenacci, 2006: 21).

Esta definición ubica a la política social en la producción del proceso de integración social como un modo de gobierno (por ende, no naturaliza este proceso) y un tipo de intervención, desligándose de verla como la expresión de algo que la excede o dentro de un juego de inputs/outputs. Desde nuestro punto de vista, lo fundamental es que no se entienda la integración como una necesidad (histórica o ética) sino como un resultado histórico y articulador de contingencias (por ende, también, fundamento y parte de las imaginaciones de quienes interceden en la invención de las políticas). Para estos autores, el Estado social engendró tres tipos o modalidades de políticas sociales que continúan operando: políticas de trabajo, políticas de servicios universales (educación, salud, infraestructura) para asegurar estándares mínimos de vida y políticas de 
asistencia que surgieron como un modo de transferencia de bienes y servicios a quienes no eran absorbidos por el mercado de trabajo (Soldano y Andrenacci, 2006: 16). En este trabajo nos centraremos en la primera de estas políticas.

\section{Un PANORAma general De La POStguerra en ARgentina}

La guerra de Malvinas fue el conflicto bélico que enfrentó, entre el 2 de abril y el 14 de junio de 1982, a las Fuerzas Armadas de Argentina y al Reino Unido por la soberanía del archipiélago conformado por las Islas Malvinas, Georgias y Sandwich del Sur. Por el lado argentino se movilizó un total de 23.405 hombres, de los cuales 10.289 correspondieron al Ejército, 10.596 a la Armada Naval, 2.314 a la Fuerza Aérea, 65 provinieron de la Gendarmería Nacional y 141 de Prefectura Naval ${ }^{2}$. Es importante destacar que este conflicto confrontó a dos Fuerzas Armadas de conformaciones diferentes (más allá de los recursos técnico-militares). Por su lado, la Argentina entró en guerra con un sistema de conscriptos (una mixtura entre soldados profesionales y civiles bajo el servicio militar obligatorio); por el suyo, el Reino Unido contaba con un ejército enteramente profesional. Esta aclaración nos permite especificar una clase particular de veterano de guerra en la Argentina: el exsoldado conscripto. Como muestran Lafferriere y Soprano (2014), el servicio militar tuvo carácter obligatorio en la Argentina desde 1901 (Ley 4.031) hasta 1994, y fue no solo un:

"Dispositivo de nacionalización de amplios sectores y de
control social, sino un componente decisivo en la
construcción de un Ejército conformado por profesionales
(oficiales y suboficiales) y por tropa compuesta por
ciudadanos/soldados conscriptos en el marco de una política
de defensa nacional fundada en el concepto del 'pueblo en
armas"' (ibídem: 2).

Los soldados profesionales argentinos poseen un marco regulatorio que define, entre otras cosas, todo su universo laboral (escalafones, criterios de retiro, etc.) al interior de las Fuerzas Armadas y los grados de cobertura médica en caso de incapacidad y la obligatoriedad de la atención (hablamos de la Ley 19.101 y sus modificatorias). Este marco

\footnotetext{
${ }^{2}$ Los dos últimos corresponden a las Fuerzas de Seguridad (y no Fuerzas Armadas) y se sitúan bajo el mando del poder civil, aunque esto queda desactivado bajo un gobierno dictatorial.
} 
era inexistente para los conscriptos en 1982, lo cual abonó el terreno de disputas e invenciones en la materia al finalizar el conflicto. Para dar una dimensión de los afectados por este vacío legal basta con mostrar el número de conscriptos movilizados por cada fuerza: de los 10.289 pertenecientes al Ejército, 7.540 fueron soldados conscriptos y 76 eran civiles cumpliendo funciones; en la Armada, de los 10.596, 3.540 eran conscriptos y 469 civiles; y de los 2.314 movilizados por la Fuerza Aérea, 459 era conscriptos y 48 civiles $^{3}$. Todo esto arroja un total de 11.539 conscriptos y 595 civiles que no contaban con marcos de protección social previstos por ley, es decir, más del $50 \%$ de los protagonistas de la guerra.

Como indican algunos autores, estos conscriptos se convertirían en el rostro de la postguerra y el cuerpo por donde pasaron las disputas y la caída del régimen militar. Recordemos que entre 1976 y 1983 la Argentina estuvo bajo el control político de una dictadura cívico-militar que se autodenominó Proceso de Reorganización Nacional, y para autores como Guillermo O'Donnell (1989), la derrota en la guerra de Malvinas fue el factor que hizo colapsar el gobierno de la Junta Militar y aceleró el regreso de la democracia. Ese colapso institucional se plasmó en la rápida renuncia del dictador Leopoldo Galtieri, su reemplazo por Reynaldo Bignone y el llamado a comicios que finalmente se efectuaron en octubre de 1983. El 10 de diciembre de ese año asumió Raúl Alfonsín (Unión Cívica Radical) como presidente electo por la ciudadanía.

Sumado a ello, la derrota en Malvinas significó, en palabras de Lucrecia Escudero Chauvel, el cierre de un capítulo de la historia discursiva argentina definida como "apogeo y crisis del discurso militar" (1996: 39). Esta inscripción de un discurso autoritario y la necesidad de un rápido rearmado del funcionamiento institucional del país se constituyeron en las condiciones de producción de la práctica política en la inmediata postguerra, marcada por una algarabía democrática, crisis económica y descontento hacia los militares. En ese entretejido, los años posteriores a la guerra fueron marcados por políticas ambiguas y cambiantes respecto a la soberanía de Malvinas y también al futuro de las Fuerzas Armadas en el país.

Respecto a Malvinas, la política exterior argentina intentó volver inmediatamente a la situación anterior a la guerra poniendo el problema

\footnotetext{
${ }^{3}$ Recuperado de: http://www.mindef.gov.ar/malvinas.php. 
en la órbita de organismos multilaterales como el Comité de Descolonización de la Organización de las Naciones Unidas (ONU). El gobierno de Alfonsín (1983-1989) alternó entre estrategias de distancia y cercanía para con los isleños y Gran Bretaña en general y la cuestión de la soberanía siempre fue una traba para restablecer las relaciones comerciales con los británicos. Este aspecto se modificó con la presidencia del justicialista Carlos Menem (1989-1999), que optó por el bilateralismo y las Ilamadas estrategias de "seducción" para los habitantes de Malvinas. Durante su presidencia se restablecieron las relaciones con los británicos mediadas por el gobierno estadounidense, bajo el "paraguas" de la soberanía que imponía reanudar el diálogo comercial sin abordar la disputa. No obstante, el reclamo de soberanía sobre las islas se estableció como mandato en la reforma constitucional de 1994. Por su parte, el gobierno del radical Fernando de la Rúa (19992001) alternó entre el bilateralismo (acercamiento y diálogo con el laborista Tony Blair y algunos acuerdos comunes) y el multilateralismo (nuevas presentaciones en la ONU), pero sobre todo optó por un abandono en la estrategia de seducción. Finalmente, tanto el gobierno Néstor Kirchner (2003-2007) como el de Cristina Fernández (2007-2015) estuvieron marcados por la opción multilateralista, el fin de los acuerdos de explotación mutua de hidrocarburos y el firme reclamo soberano (Simonoff, 2014).

En lo referente a la política estatal y su relación con la cuestión militar, para Sabina Frederic el gran problema "desde 1983 ha sido cómo conducir a las Fuerzas Armadas en un régimen democrático, evitando conspiraciones golpistas; [es decir] cómo integrar —subordinadamente- a los militares al Estado democrático" (2013: 52). Para la autora, la postguerra y los recuerdos de los horrores cometidos por los militares argentinos durante la dictadura condicionaron las políticas referidas a ese sector cruzado por el descrédito social, exclusión de los recursos estatales y un éxodo progresivo de jóvenes efectivos. Entre los hitos más relevantes para el sector se destacaron el desmantelamiento y reducción presupuestaria, la suspensión del servicio militar obligatorio, las leyes de reestructuración de las fuerzas y la elaboración de un nuevo código de disciplina más "ciudadano", entre otros. 

LOS VETERANOS DE GUERRA

Coexistiendo con la tensión y la ambigüedad respecto a Malvinas y a las Fuerzas Armadas, los exconscriptos partícipes de la guerra ocupaban un lugar novedoso en la política argentina. Algunos autores (Menéndez, 1998; Guber, 2001, 2004; Lorenz, 2012; Rodríguez, 2014) coinciden en que durante los primeros años de postguerra la sociedad y el gobierno construyeron al veterano como víctima no solo de los británicos, sino fundamentalmente de las Fuerzas Armadas, y esta victimización fue parte de la línea de frontera que les permitió, intentando romper esa imagen, erigir sus identidades como grupo. Estos estudios se han ocupado de analizar el fenómeno de los veteranos en la inmediata postguerra centrándose en el problema de la identidad, cruzado por imaginarios sociales, ritos culturales o prácticas de identificación grupal, por lo que el Estado aparece como un actor más en algún discurso presidencial, disputa mediática o acción puntual (la aprobación de alguna ley), sin focalizar en la continuidad del pensamiento político sobre el papel o lugar que le cabe a este sujeto emergente de la guerra. Este artículo se plantea desarrollar esa vacancia.

Recordemos que planteamos al inicio la intención de abordar nuestro corpus de documentos estatales -entendidos como dispositivos de protección social- desde dos niveles: cómo se presentan los problemas y cómo se induce a actuar. Estos niveles funcionan como una inferencia hipotética desde la cual iremos identificando los términos utilizados, los argumentos expuestos, los caminos propuestos, siempre tomando en cuenta la relación entre trabajo y excombatientes. Esa identificación a nivel del discurso es un reconocimiento de marcas, es decir, un conjunto de "procedimientos que exponen a la mirada lectora niveles opacos a la acción estratégica de un sujeto" (Narvaja de Arnoux, 2009: 19), por lo que intentaremos encontrar puntos en común entre esas marcas a los que denominaremos regularidades.

Nuestro corpus se conforma con 26 documentos estatales, de los cuales siete son leyes ${ }^{4}$, seis decretos ${ }^{5}$ y 13 resoluciones $^{6}$ (que incluyen modelos

\footnotetext{
${ }^{4}$ Ley 22.674 (subsidio extraordinario para personas con inutilización o disminución psicofísica permanente, como consecuencia de su intervención en el conflicto con el Reino Unido); Ley 23.017 (pensión vitalicia para determinados ciudadanos que como consecuencia de las acciones bélicas en las Islas Malvinas resultaron disminuidos para el trabajo); Ley 23.109 (beneficios a exsoldados conscriptos que han participado en las 
de formularios y desarrollo de programas laborales), del período abarcado desde diciembre de $1983^{7}$ hasta febrero de 2011. El grado de institucionalidad de estos documentos no le quita potencia como dispositivo, puesto que el marco legal siempre afecta la vida de las personas sobre todo al tratarse de un sujeto con características particulares como el excombatiente. Aunque el presidencialismo no sea tema de este estudio, el período comprende los mandatos de Raúl

acciones bélicas desarrolladas en el Atlántico Sur); Ley 23.598 (pensión vitalicia para determinados ciudadanos que sufrieron incapacidades permanentes con motivo de las acciones bélicas en el Teatro de Operaciones del Atlántico Sur); Ley 24.013 (ley nacional de empleo); Ley 24.310 (pensión graciable vitalicia a ciudadanos argentinos que sufrieron incapacidades con motivo de las acciones bélicas en el Teatro de Operaciones del Atlántico Sur); Ley 24.465 (régimen de contrato de trabajo y modalidad especial de fomento del empleo).

${ }^{5}$ Decreto 509/1988 (reglamentación de la Ley 23.109 que acordará beneficios a los exsoldados conscriptos que han participado en las acciones bélicas desarrolladas en el Atlántico Sur); Decreto 2.476/1990 (racionalización de Administración Pública); Decreto 738/1995 (reglamentación de la Ley 24.465, modalidad especial de fomento de empleo); Decreto 1.244/1998 (beneficio mensual para el personal que acredite la condición de excombatiente); Decreto 565/2002 (creación del Programa Jefes de Hogar); Decreto 886/2005 (compatibilidad de la pensión de guerra con cualquier otro beneficio de carácter previsional).

${ }^{6}$ Resolución 1.605/1990, Ministerio de Salud y Acción Social (incorpórese a la población de veteranos de guerra como población objeto de los programas sociales del Ministerio de Salud y Acción Social); Resolución 211/1998, Secretaría de la Función Pública (alcances del Decreto 1.244/1998); Resolución 3/1999, Secretaría de la Función Pública (formulario que deberá ser completado por los agentes excombatientes que reúnan las condiciones previstas por el Decreto 1.244/1998); Resolución 78/1999, Secretaría de la Función Pública (modificase el formulario aprobado por Resolución 3/1999); Resolución 597/1999, Ministerio de Trabajo y Seguridad Social (pensión vitalicia concedida a excombatientes es compatible con la prestación por desempleo regulada por Ley 24.013); Resolución 4/2001, Subsecretaria de la Gestión Pública (procedimiento relativo a la solicitud del complemento previsto en el Decreto 1.244/1998 para el personal que acredite la condición de excombatiente); Resolución 13/2001, Secretaría para la Modernización del Estado (aclaración sobre la incompatibilidad incorporada por el Decreto 894/2001, la que no comprende a la percepción de la pensión de guerra); Resolución 312/2002, Ministerio de Trabajo, Empleo y Seguridad Social (reglamentación del Programa Jefes de Hogar); Resolución 1.002/2002, Honorable Congreso de la Nación Argentina; Resolución conjunta 91/2002 y 284/2002; Resolución 102/2006, Secretaría de Empleo (manual operativo del Programa de Empleo Comunitario y de los formularios de presentación de proyectos); Resolución 175/2008, Secretaría de Empleo (parámetros para las empresas y los talleres protegidos de producción); Resolución 294/2011, Secretaría de Empleo (proyectos para las Empresas y los talleres protegidos de producción).

${ }^{7}$ A excepción de la Ley 22.674 sancionada en 1982 por la Comisión de Asesoramiento Legal, organismo que se encargaba de la promulgación de leyes, resoluciones y disposiciones durante la dictadura que clausuró el funcionamiento del Poder Legislativo democrático. Su inclusión se justifica por funcionar como un antecedente que se liga al resto de las leyes sobre incapacidad física. 
Alfonsín (1983-1989), Carlos Menem (1989-1999), Fernando de la Rúa (1999-2001), Eduardo Duhalde (2001-2003), Néstor Kirchner (2003-2007) y parte del de Cristina Fernández (2007-2015).

Antes del análisis caben algunas aclaraciones previas. En principio, nuestro objetivo es centrarnos en el Estado nacional, lo que no descarta la importancia y participación de los mismos veteranos en la concreción de políticas específicas y tampoco desmerece la actuación de los Estados provinciales argentinos. La nuestra es una decisión sobre dónde mirar. A su vez, entendemos que existieron y existen diversos planos desde donde observar las políticas sociales (no solo sobre la especificidad de intervención, i.e., salud, educación, previsión social, vivienda, etc.; también en la definición conceptual de su alcance) pero nosotros optamos por atender el plano del trabajo, adscribiendo a la posición de Castel (2010) sobre la importancia de lo laboral en la gran pregunta por la cohesión. En ese sentido, quedarán aspectos que podrán ser retomados en otros trabajos que tengan otras pretensiones.

Desde nuestra lectura pudimos establecer cinco regularidades desde donde, entendemos, se gobernó a los veteranos de guerra a partir de los dispositivos de protección social ligados al problema del trabajo. Si bien podemos datar estas regularidades, su orden no es específicamente cronológico ya que algunas se dan en simultáneo, lo que nos muestra la multiplicidad del despliegue de las relaciones de poder.

\subsection{Primera regularidad: la conexión entre la incapacidad física y la capacidad de trabajar}

En los primeros años de postguerra se promulgaron cuatro leyes sobre pensiones que atendian al problema de la incapacidad de los veteranos civiles provenientes de la guerra. El problema emergente era detectar y subsanar aquello que afectaba su capacidad de volver al mercado de trabajo. Las diferencias entre las leyes se dieron en un doble sentido: sobre quiénes legislar y dónde establecer la equivalencia en el ingreso. Respecto a este último punto, la Ley 22.674 (de 1982) dispuso que la pensión equivaldría a un haber mensual del grado de teniente general o equivalentes; la Ley 23.017 (de 1983) ubicó la pensión en los marcos del haber mínimo de jubilación ordinaria al igual que la Ley 23.598 (de 1988); en cambio, la Ley 24.310 (de 1994) vuelve a ubicar la pensión en la equivalencia de los ingresos militares al equipararla con un haber mensual del grado más bajo de la jerarquía de suboficial, con dos años 
de servicios militares en el grado. Esta última ley, a diferencia de las primeras tres, no establece como problema la legislación sobre determinados ciudadanos sino que se pensiona por incapacidad en general, abriendo el marco legal a todos los que tuvieron secuelas físicas y psicológicas producto de su participación en la guerra de Malvinas ${ }^{8}$.

Este punto se hace diferencial en el plano de las acciones sobre acciones, sobre todo en la exhortación a demostrar la incapacidad. La Ley 22.674 establece una tabla donde se ubica la variabilidad de ingreso a partir del porcentaje de incapacidad. Corresponde al veterano -a partir del diagnóstico médico-demostrar ese porcentaje:

\begin{tabular}{cc}
\hline Por porcentaje de incapacidad & Por porcentaje a liquidar \\
\hline 10 a $19 \%$ & $40 \%$ \\
20 a $29 \%$ & $50 \%$ \\
30 a $39 \%$ & $60 \%$ \\
40 a $49 \%$ & $70 \%$ \\
50 a $59 \%$ & $80 \%$ \\
60 a $65 \%$ & $90 \%$ \\
\hline
\end{tabular}

Fuente: Ley 22.974 (Artículo 2)

Esa instrucción reglamentaria no ingresa en las leyes 23.017 y 23.598, las cuales definen que "determinados ciudadanos" serán beneficiarios ( 25 en la primera, 20 en la segunda) y publica la lista en su articulado. Por su parte, la Ley 24.310 cierra parcialmente el tema y ya no pone el

\footnotetext{
${ }^{8}$ En nuestro análisis no se considera el funcionamiento legislativo en el sentido de atender especialmente el reemplazo de ciertas leyes por otras, ya que las entendemos como dispositivos que echan luz sobre distintos momentos de afectación de la conducta de los excombatientes. De todas formas, cabe señalar que ninguna de estas leyes reemplazó o complementó a la anterior.
} 
problema de la incapacidad en el plano del trabajo (escindiendo, a nuestro modo de ver, trabajo de salud) a la par que reabre la posibilidad de solicitar la pensión al conjunto de exsoldados incapacitados por sus acciones bélicas. A pesar de ello, en el anexo I de la ley, se publica una nómina de veteranos beneficiados. Recién en 2008 fue la Resolución $1.237 / 2008$ del Ministerio de Defensa la que dio un marco regulatorio específico y con pasos definidos para quienes reunieran condiciones de ingresar en este beneficio. Aunque esta descripción excede los límites de nuestro trabajo.

\subsection{Segunda regularidad: las prioridades en el terreno laboral}

El 29 de septiembre de 1984 se sancionó la Ley 23.109, que estableció "beneficios a exsoldados conscriptos que han participado en las acciones bélicas desarrolladas en el Atlántico Sur entre el 2 de abril y el 14 de junio de 1982". El proyecto original fue presentado por el senador Orlando Britos (Partido Justicialista), quien fundamentó el pedido a partir de entender que

"Todo el pueblo argentino coincidió en la justicia de ese objetivo [la recuperación de Malvinas] y es ese mismo pueblo quien debe agradecer a los argentinos que se armaron en su defensa (...) la defensa de la soberanía nacional en el campo de batalla por nuestros soldados es una acción que el Estado y el pueblo argentino deben recordar y reconocer, no solo a través de manifestaciones públicas, sino fundamentalmente por medio de disposiciones que impliquen contemplar y buscar soluciones a su especial problemática, derivada de dicho conflicto"'.

Una parte del problema a solucionar tuvo que ver con el marco laboral y con ciertos derechos que no son alcanzados.

Como señala Bal Sokhi-Bulley (2016), el derecho se convierte en una tecnología de gobierno al instituir a los sujetos de derecho como sujetos identificables y gobernables (a través del derecho), pero sobre todo al asentar el discurso en una verdad que parece universal. Trabajo y derecho se entretejen en el discurso de esta ley estableciendo una

\footnotetext{
${ }^{9}$ Hemos decidido obviar en este trabajo las transcripciones de las sesiones ordinarias del Congreso en el tratamiento de algunas de las leyes que analizamos por cuestiones de espacio y de convicción respecto a lo efectivamente legislado. Lo cual no quiere decir que no podamos recuperarlas en estudios posteriores. No obstante, creemos necesario resaltar las palabras de Britos por su alusión a una problemática especial como fondo común para hablar sobre los veteranos de guerra (Proyecto de Ley. Expte. S-404-84).
} 
equivalencia entre derechos merecidos por los veteranos e institución de prioridades laborales en la administración pública ${ }^{10}$. En esa conexión se marca su definición como sujeto prioritario por encima de otros (que no están definidos).

Por su parte, y en el plano de las acciones sobre acciones, para que derecho y trabajo se conecten a través de la prioridad, los veteranos debian reunir determinadas condiciones y actuar de una forma específica. Debían poseer las cualidades y experiencia de acuerdo a la vacante en la administración pública y presentar junto a la solicitud de empleo el documento que certifique su condición de veterano de guerra (Decreto 509/1988). Esta ley, y su correspondiente decreto, instruye y conforma un espacio donde, desde la igualdad de oportunidades, se prioriza a los excombatientes. Esta prioridad irá convirtiéndose, en el plano de lo laboral, en una característica especial con tendencia a nombrar a los veteranos de guerra como grupo vulnerable.

\subsection{Tercera regularidad: veteranos de guerra como grupos vulnerables}

En 1990 se sancionó la Ley 23.848 que, por primera vez, estableció una pensión graciable para los veteranos de guerra. Esta ley los ubicó dentro del régimen previsional argentino y bajo el gran marco de las pensiones no contributivas. Si bien nosotros no analizaremos este aspecto, es necesario resaltarlo porque coincide con la tendencia a ser tratado como grupo vulnerable que tendrá este colectivo bajo el paraguas de la protección del empleo. Emergieron dispositivos que no pusieron a la prioridad como meta, sino a la promoción por una especial condición desfavorable. Esto coincide con la noción de handicapología de Castel: el nacimiento de la asistencia social estuvo marcado por un modo de diferenciar (y por ende justificar la acción de asistir) a los asistidos (1995: 287). No se trata ya de la pertenencia a un grupo que podría activarse por su cuenta, sino de una activación que necesita del Estado y va conectándose con la construcción de un tipo de grupo vulnerable que merece atención.

\footnotetext{
${ }^{10}$ Rosana Guber (2004) indica que el Estado militar dio trabajo a numerosos veteranos en las empresas públicas nacionales de servicios (la telefónica ENTEL o Gas del Estado) y en otras como el Banco Nación o la Policía Federal. Si bien el período 1982-1983 es importante, excede las pretensiones de análisis de este trabajo centrado en la democracia.
} 
Parte de esta problematización se fue tejiendo en la Resolución 1.605/1990 del Ministerio de Salud y Acción Social -fomentada por la Federación de Veteranos de guerra de la República Argentina- ${ }^{11}$ donde se ubicó como problemático el hecho de que el conflicto bélico dio origen a un grupo de ciudadanos con características diferentes del resto de la población (en cuanto a sus vivencias, secuelas físicas y psicológicas) que dieron nacimiento a necesidades diferenciales. Ya no se pide prioridad ni tratamiento por incapacidad para un grupo específico de beneficiarios: todos merecen especial atención en los programas del gobierno. Y si bien esta regulación no se mueve en el terreno laboral, su inscripción puede verse en la Ley 24.013 (Ley Nacional de Empleo sancionada en 1991) que constituyó el antecedente de las regulaciones de flexibilización labor a ${ }^{12}$ que caracterizaron a la Argentina de los 90. Esta ley estableció la conformación de un programa de empleo para "grupos protegidos" de trabajadores, cuyas características los ubican entre quienes tienen mayores dificultades de inserción laboral (art. 85) y marcan la necesidad de protección definiendo al trabajo como factor de integración social. En ese plano ingresan los excombatientes, a quienes se los emplaza en un mismo nivel de equivalencia que otros merecedores de protección: exconvictos liberados, poblaciones aborígenes y sujetos rehabilitados de la drogadicción. Si la Ley 23.848 (de pensión graciable) los ubicó cercanos a los jubilados (ingresaron bajo este estatuto), la equivalencia en el marco laboral (el hecho de compararlos con otros) aparece como justificación por primera vez al modificar el argumento de protección: los veteranos tienen particularidades especiales, pero equivalentes a otras, lo cual se repetirá en programas similares que toman en cuenta "la situación especial de sus beneficiarios y el carácter del trabajo como factor de integración social" (Ley 24.013).

En 1995 surgieron las llamadas leyes de flexibilización laboral, entre las cuales se ubican modificaciones en modalidades de contratación y el

\footnotetext{
${ }^{11}$ La Federación de Veteranos de la Guerra de Malvinas es un organismo surgido en la década de 1990 que agrupa veteranos de la guerra del Atlántico Sur. Fue el primer espacio reconocido por el Estado como aglutinador de reclamos del sector, lo cual lo puso en disputa con otros movimientos similares de excombatientes. Ver Guber, 2004; Lorenz, 2012.

${ }^{12}$ En Argentina, como en otros países de América Latina, durante la década de 1990 se modificaron las legislaciones sobre condiciones de contratación, seguridad laboral, remuneraciones, etc. Entre otros, ver: Frenkel y Ros, 2004.
} 
programa "Modalidad Especial del Fomento del Empleo", regulado por la Ley 24.465. Este dispositivo actualiza la necesidad de fomentar el empleo entre grupos especiales, equiparando esta vez a excombatientes con trabajadores mayores de cuarenta años, personas con discapacidad y mujeres. Su decreto de promulgación (738/1995) amplía la problematización ya que esa "modalidad especial" pedirá la certificación de la identidad de excombatientes.

A nivel de las acciones sobre acciones, los dispositivos desplegados se extienden desde la presentación individual ante un colectivo de representación hasta la estandarización de las solicitudes a través de la implementación de un formulario. Si la Resolución 1.605/1990 del Ministerio de Salud y Acción Social estableció los primeros pasos hacia la vulnerabilidad y la institución de los veteranos como población objeto de los programas sociales, aún los escalones para acceder son inciertos: se exhorta a presentarse ante la Federación de Veteranos de Guerra de la República Argentina, que avalará los requerimientos de asistencia. Es decir, todavía había una mediación y colectivización en el qué hacer.

En cambio, las leyes 24.013 y 24.465 -por su carácter de marco para el contrato entre sujetos- establece mayor especificación: aceptar el "contrato especial" $y$, sobre todo, certificar su condición de excombatiente de Malvinas mediante el documento expedido por la Fuerza Armada donde sirvió en batalla. Esta demarcación del qué hacer se hace más concreta con el Decreto 738/1995, al aparecer un dispositivo específico y que por primera vez deja de ser emitido por el Ministerio de Defensa: el formulario de acreditación como excombatiente. Este formulario - modelo del contrato de trabajo que firmarán empleador y empleado- da inicio en el plano laboral a la identificación concreta de un excombatiente como tal.

\subsection{Cuarta regularidad: homenaje y trabajo en la identificación del multinombrado}

Según consta en el Decreto 1.244/1998, la Federación de Veteranos de Guerra de la República Argentina solicitó que se otorgara un beneficio mensual a los excombatientes incorporados a la Administración Pública Nacional en el nombre de la justicia y el reconocimiento. Este pedido se materializó, pero necesitó de un despliegue de dispositivos que hicieron del reconocimiento una necesidad. La Resolución 211/1998 de la Secretaría de la Función Pública de la Jefatura de Gabinete de Ministros 
estableció la necesidad de precisar los alcances del decreto, y la Resolución 3/1999del mismo organismo actualizó ese problema. El mecanismo utilizado fue la implementación de un formulario que debía ser completado por los excombatientes -definidos en términos de agentes - que desearan el beneficio. De esta forma vemos cómo se conectan el trabajo estatal de los veteranos con la necesidad de homenaje.

Esa conexión se encadena con otro problema, quizá, inesperado: la indefinición de cómo nombrar a los potenciales beneficiarios, ya que su denominación alternaba (excombatientes, veteranos de Malvinas, veterano de guerra, exsoldado conscripto, etc.) y también las características para ser considerados como tales (civiles o militares, movilizados o partícipes de batallas, etcétera).

Esto emerge de las resoluciones 78/1999 (Secretaría de la Función Pública de la Jefatura de Gabinete de Ministros) y 4/2001 (Subsecretaría de la Gestión Pública de la Secretaría de Coordinación General de la Jefatura de Gabinete de Ministros), que establecen la necesidad de agilizar la inserción de los datos por parte del interesado por lo cual se decide incorporar en un anexo las certificaciones de los organismos intervinientes, donde conste que se cumple con los requisitos. Del hiato entre homenaje y trabajo surge la indefinición de cómo denominar a esos "trabajadores homenajeados"; por primera vez se redacta un ítem de aclaración, puesto que en diferentes documentos aparece indistintamente el término veterano o excombatiente:
"A los fines de la percepción del beneficio previsto se aclara que los términos: excombatientes, veteranos de guerra 0 veteranos de Malvinas son sinónimos. Entendiéndose por tales a todo aquel personal de oficiales, suboficiales y soldados de las Fuerzas Armadas y de Seguridad que haya participado de las acciones bélicas (...) y civiles que se encontraban cumpliendo funciones de servicios y/o apoyo en donde se desarrollaron las acciones" (Conf. Ministerio de Defensa. Nota 27/5/1999).

Esta aclaración técnica y terminológica es la primera que se hace desde el fin de la guerra y surge de un problema ateniente al plano del trabajo, conectando el uso de formularios donde consta la calidad de veteranos de guerra con la necesidad de homenaje y el terreno de los trabajadores de la administración pública. En ese sentido, las acciones sobre acciones fueron marcando ese surgimiento: el Decreto 1.244/1998pedía acreditar 
la condición de "veterano de guerra", mientras que la Resolución 211/1998 solicitaba certificar la condición de "excombatiente que hubiera participado efectivamente en las acciones bélicas de combate". Además, el pedido de datos empieza a establecer puentes entre el Ministerio de Defensa y la Jefatura de Gabinete (Resolución 3/1999) hasta estandarizar en un solo dispositivo la hoja de vida del interesado.

Finalmente, tres años después del Decreto 1.244/1998 y tras resultados aclaratorios emergentes, la Resolución 4/2001 de la Subsecretaría de la Gestión Pública definió finalmente la estructura de la presentación: el interesado debía llevar el formulario al Área Veteranos de Guerra de las Fuerzas Armadas para su registro y certificación; luego a su lugar de trabajo.

\subsection{Quinta regularidad: de lo incompatible a la omnicompatibilidad}

Las leyes 23.598 (de 1988) y 24.310 (de 1994), ambas -como vimossobre incapacidad laboral, plantearon el problema teniendo en cuenta la incompatibilidad de la pensión otorgada a los veteranos tanto con cualquier pensión de carácter previsional, como con otras ligadas a la participación en las acciones bélicas. En conexión con estos argumentos, la compatibilidad como problema también aparece en los programas de fomento al empleo que desarrollamos en la tercera regularidad. Estos programas negaban su participación a los beneficiarios de pensiones no contributivas, dentro de los cuales estaban incluidos los excombatientes de Malvinas.

Sin embargo, esto empezó a modificarse en regulaciones posteriores que exceptuaron a los veteranos. Por ejemplo, al tratar el problema de bajar el gasto público, el Decreto 2.476/1990 (de "racionalización administrativa") estableció la reducción en la masa salarial para quienes pasaran a planta permanente en la Administración Pública. Sin embargo, atendió a la "especial situación de los excombatientes" quienes quedaban exceptuados. En la misma línea, la Resolución 597/1999 del Ministerio de Trabajo y Seguridad Social, que estableció incompatibilidades entre las prestaciones por desempleo y "beneficios" ligados a pensiones, y la Resolución 13/2001 de la Secretaría de Modernización del Estado (Jefatura de Gabinete de Ministros) pone de relieve el problema establecido por el Decreto 894/2001 y define la incompatibilidad entre la percepción de un beneficio previsional con el 
desempeño de un cargo público nacional. También podemos agregar la Resolución 1.002/2002 de la Cámara de Diputados de la Nación, que prohibió la acumulación de cargos en el Poder Legislativo. Estos cinco dispositivos conectan con la necesidad de "racionalizar" los gastos pero también implican excluir a los veteranos de guerra.

Este planteamiento se actualiza en algunos programas de empleo que surgieron posteriormente, poniendo a la compatibilidad en el plano de la equivalencia con otros casos especiales. Dos ejemplos claros son el programa Jefes y Jefas de Hogar creado por Decreto 565/2002, que negó la posibilidad de ser beneficiarios a quienes se encontraran percibiendo prestaciones previsionales, de desempleo o pensiones no contributivas. Sin embargo, la resolución conjunta 91/2002 y 284/2002 (Ministerio de Trabajo, Empleo y Seguridad Social y Ministerio de Desarrollo Social, respectivamente) estableció tres excepciones: madres de siete o más hijos, inválidos y excombatientes. Esta compatibilidad se replicó en la Resolución 102/2006 de la Secretaría de Empleo, que estableció el "Manual Operativo del Programa de Empleo Comunitario (PEC)", cuyo problema era afrontar situaciones locales transitorias de emergencia ocupacional. Este programa también exceptuó a quienes percibieran otros beneficios de la seguridad social o pensiones no contributivas, pero se movía por la misma compatibilidad que el anterior: madre de siete hijos, invalidez, excombatientes. Lo mismo sucede con el programa Empresas y Talleres Protegidos de Producción (Resolución 175/2008, Secretaría de Empleo del Ministerio de Trabajo, Empleo y Seguridad Social) y con otros programas de empleo posteriores.

Tiempo antes, el Decreto 886/2005 había generado un movimiento aglutinador al compatibilizar las pensiones de guerra con cualquier beneficio social o laboral que poseyera el excombatiente. Este decreto partió de entender que existía una situación socioeconómica excepcional que afectó a los sectores de menores ingresos, entre los que figuran los veteranos de guerra. Asimismo, la pensión era vista como un reconocimiento por los servicios prestados a la patria. Estas dos conexiones abren el plano de la compatibilidad: no puede haber prestación previsional o de retiro, o ingreso alguno en cualquier plano (nacional, provincial o municipal), que la anule. La omnicompatibilidad se presenta como una muestra de reconocimiento patriótico. 


\section{LA METAMORFOSIS DEL PROBLEMA VETERANO}

En este texto propusimos un análisis del gobierno de los veteranos argentinos de la guerra de Malvinas a partir de observar regulaciones legales en el plano del trabajo, que fueron abordadas entendidas como "dispositivos de protección social". Nuestro estudio partió del enfoque de la gubernamentalidad y desde alli describimos los problemas y las "acciones sobre acciones" presentes en el discurso de un corpus de leyes, decretos y resoluciones de diferentes organismos del Estado nacional argentino promulgados entre 1983 y 2011.

Pudimos establecer cinco regularidades que marcaron el campo posible de gobierno de los veteranos de guerra: la conexión entre la incapacidad física y la capacidad de trabajar, la definición de los excombatientes como grupo prioritario, la estabilización de los veteranos en tanto población vulnerable, el homenaje y el trabajo en la identificación del multinombrado y la demarcación de una especie de omnicompatibilidad sobre este colectivo. En esas demarcaciones pudimos ver desde delimitaciones concretas (armados de listas con nombre y apellido) hasta estandarizaciones de datos a partir de formularios, que conjugaron una parte del abanico de dispositivos que operaron sobre los veteranos de Malvinas desde el fin de la guerra.

El corpus analizado nos permite afirmar que el dispositivo de protección social desplegado tendió a un gobierno de los veteranos como sujeto focalizado y con marcas físicas y simbólicas específicas que lo ubicó entre los necesitados de protección estatal. Al definirlo como un sujeto focalizado nos referimos al desarrollo de políticas que promovieron su individualización y comparación con otros desprotegidos, regularidad de acción estatal que define las políticas de individuación (Merklen, 2013) como marca distintiva del neoliberalismo. Esta individuación nació al calor de la postguerra, con una identificación puntual (listas con nombre y apellido) de sujetos con incapacidades físicas que no les permitían reinsertarse en la sociedad por vía del gran mecanismo de socialización: el trabajo (Castel, 1995). La problematización de los veteranos como sujetos con secuelas no los abandonará como argumento básico de los dispositivos analizados y se tejerá en las regularidades que señalamos, dando cuenta de una metamorfosis del tratamiento estatal hacia los veteranos de Malvinas (lo que podríamos llamar el problema veterano). Tomamos la definición de metamorfosis de Castel al entender que los cambios históricos "no son novedades absolutas si se inscriben en el 
marco de una misma problematización" (ibídem: 19) que hay que identificar.

En ese sentido, la primera regularidad que marcamos ligaba lo sanitario en directa relación con el problema laboral, por lo cual la salud deficitaria anulaba directamente la posibilidad de trabajar. De allí que la solución planteada fuera la pensión por incapacidad. Por supuesto que esta incapacidad no tocaba a todos los veteranos de guerra por igual por obvias razones: no todos los excombatientes fueron heridos, mutilados o disminuidos físicamente. Sin embargo, el despliegue de la marca se movió hacia una disminución más opaca: la psicológica y la social. De allí que la segunda regularidad los pusiera como un sujeto prioritario, emplazado todavía dentro del imaginario del gran Estado benefactor argentino. El trabajo estatal (no privado, no promovido por programas como los de la década de 1990) se ponía como el horizonte adecuado para el ingreso de esta masa de veteranos a quienes se ubicaba como desprotegidos. A diferencia de la primera regularidad (donde salud y trabajo fueron indisociables), aquí el trabajo como aglutinador social se desplegaba sobre los veteranos civiles.

No es extraño entonces que en la década de 1990 los programas de racionalización y promoción del empleo los ubicaran en un lugar especial: en el reino de los pobres y necesitados. Las especiales marcas de guerra que los veteranos traen consigo los ponen en equivalencia con los demás sujetos en riesgo de desafiliación (expresos, aborígenes, exdrogadictos, trabajadores mayores de cuarenta años, discapacitados y mujeres). Esas marcas no son solo físicas (la incapacidad), sino que se ligan a la definición de prioridad con que las leyes de la década de 1990 enunciaban la especial problemática de los veteranos. Pero esa prioridad era relacionada con otro sujeto inexistente e indefinido, cuestión que se modifica en la década posterior. Por ende, esa tercera regularidad trae un modo de ver el cuerpo y la marca simbólica y agrega un atributo: la del grupo desprotegido, especial y vulnerable, sobre el que debe recaer la promoción y el fomento, que no puede sino ser estatal. Bajo esta regularidad, las dos primeras marcas que definian su singularidad los ponen en el mismo carril de otros desprotegidos. Podríamos decir que aquello que los diferencia también los iguala con otros necesitados de asistencia, por lo cual se hace visible un vaivén constante entre rareza y equivalencia. 
Ese movimiento pendular sigue presente en las restantes regularidades que señalamos. Ambas van desde una singular marca de origen (la participación en la guerra) hasta una regular acción estatal clásica (el homenaje y el reconocimiento), y ambas tienen en el trabajo su punto de apoyo. Aparece en la contingencia de la cuarta regularidad, que desembocó en el inesperado problema de la imposibilidad de homenajear sin definir primero quién era el homenajeado. Y vuelve a emerger en la quinta, que amalgamó la pensión de guerra con la posibilidad de presentarse en programas de fomento al empleo para grupos protegidos. Las cinco regularidades muestran una problematización común: el trabajo estatal y la capacidad de trabajar fueron motores del problema veterano para evitar que estos sujetos que cumplieron una función guerrera (no laboral) para el Estado entre abril y junio de 1982- no queden por fuera de la sociedad. Asimismo, nos permiten afirmar la imposibilidad de pensar las acciones de gobierno sobre los excombatientes como homogéneos y también nos exhortan a continuar generando preguntas e indagando sobre una relación que se presenta como siempre rota: la del Estado argentino con los protagonistas de la guerra de Malvinas.

\section{Bibliografía}

Agamben, G. (2011). ¿Qué es un dispositivo? Sociológica, 26(73), 249-264.

Bröckling, U., Krasmann, S., y Lemke, T. (2011). Governamentality: current issues and future challenges. Nueva York: Routledge.

Castel, R. (1995). La metamorfosis de la cuestión social. Buenos Aires: Estado y Sociedad.

Castel, R. (2010). ¿Qué significa estar protegido? La dimensión socioantropológica de la protección social. En R. Castel (Ed.), El ascenso de las incertidumbres: trabajo, protecciones, estatuto del individuo (pp. 189-200). Buenos Aires: Fondo de Cultura Económica.

Castro Gómez, S. (2010). Historia de la gubernamentalidad. Bogotá, Siglo del Hombre.

Dreyfus, H., y Rabinow, P. (2001). Michel Foucault: más allá del estructuralismo y la hemenéutica. Buenos Aires: Ediciones Nueva Visión.

Escudero Chauvel, L. (1996). Malvinas: El gran relato: fuentes y rumores en la información de guerra. Barcelona: Gedisa. 
Foucault, M. (1999). Estética, ética y hermenéutica. Barcelona: Paidós.

Frederic, S. (2013). Las trampas del pasado: las Fuerzas Armadas y su integración al Estado democrático en Argentina. Buenos Aires: Fondo de Cultura Económica.

Frenkel, R., y Ros, J. (2004). Desempleo, políticas macroeconómicas y flexibilidad del mercado laboral. Argentina y México en los noventa. Desarrollo Económico, 44(173), 33-56.

Gordon, C. (2015). Racionalidad gubernamental: una introducción. Nuevo Itinerario, 10(X), 1-58.

Guber, R. (2001). ¿Por qué Malvinas? De la causa nacional a la guerra absurda. Buenos Aires: Fondo de Cultura Económica.

Guber, R. (2004). De "chicos" a "veteranos": memorias argentinas de la guerra de Malvinas. Buenos Aires: Antropofagia-IDES.

Lafferriere, G., y Soprano, G. (2014). El servicio militar voluntario en las Fuerzas Armadas argentinas entre el final del siglo $X X$ y principios del XXI. Conjuntura Austral, 5(24), 17-45.

Lorenz, F. (2012). Las guerras por Malvinas. Buenos Aires: Edhasa.

Menéndez, M. (1998). La "comunidad imaginada" en la Guerra de Malvinas. Buenos Aires: Eudeba.

Merklen, D. (2013). Las dinámicas contemporáneas de la individuación. En R. Castel et al. (Eds.), Individuación, precariedad, inseguridad (pp.45-86). Buenos Aires: Paidós.

Miller, P., y Rose, N. (2008). Governing Economic and Social Life. En Governing the present: Administering economic, social and personal life (pp. 1-26). Londres, Inglaterra: Polity Press.

Narvaja de Arnoux, E. (2009). Análisis del discurso. Buenos Aires, Argentina: Santiago Arcos.

O'Donnell, G. (1989). Transiciones, continuidades y algunas paradojas. Cuadernos Políticos, 56(enero-abril), 19-36.

O'Malley, P. (2006). Riesgo, neoliberalismo y justicia penal. Buenos Aires: Ad-Hoc.

Rodríguez, A. (2014). Entre la guerra y la paz: la posguerra de los excombatientes del Apostadero Naval Malvinas. Experiencias, identidades, memorias (Tesis doctoral inédita). UNLP, La Plata.

Rose, N. (2007). ¿La muerte de lo social? Re-configuración del territorio de gobierno. Revista Argentina de Sociología, 5(8), 113-152. 
Sokhi-Bulley, B. (2016). Government (through) Rights. Oxford: Hart Publishing.

Soldano, D., y Andrenacci, L. (2006). Aproximación a las teorías de la política social a partir del caso argentino. En L. Andrenacci (Comp.), Problemas de política social argentina (pp. 17-79). Buenos Aires: Prometeo-UNGS.

Simonoff, A. (2014). Continuidades y rupturas en las negociaciones argentinas hacia Malvinas (1945-2012). En L. Sanchez y F. Gómez (Eds.), Un actor ignorado: la cuestión Malvinas en el Parlamento Nacional (pp. 25-42). Buenos Aires: Prometeo Libros. 